OPEN ACCESS

Edited by:

Shiang Y. Lim,

University of Melbourne, Australia

Reviewed by:

David Grieve,

Queen's University Belfast, United Kingdom

Jarmon G. Lees,

University of Melbourne, Australia

*Correspondence:

Wei Liu

wei.liu@manchester.ac.uk

${ }^{\dagger}$ These authors have contributed equally to this work

Specialty section:

This article was submitted to

Clinical and Translational Physiology, a section of the journal

Frontiers in Physiology

Received: 13 April 2021

Accepted: 10 May 2021

Published: 21 June 2021

Citation:

Kaur N, Guan Y, Raja R, Ruiz-Velasco A and Liu W (2021)

Mechanisms and Therapeutic

Prospects of Diabetic

Cardiomyopathy Through

the Inflammatory Response.

Front. Physiol. 12:694864. doi: 10.3389/fphys.2021.694864

\section{Mechanisms and Therapeutic Prospects of Diabetic Cardiomyopathy Through the Inflammatory Response}

\author{
Namrita Kaurt, Yingshu Guant, Rida Raja, Andrea Ruiz-Velasco and Wei Liu* \\ Division of Cardiovascular Sciences, School of Medical Sciences, Faculty of Biology, Medicine, and Health, The University \\ of Manchester, Manchester, United Kingdom
}

The incidence of heart failure (HF) continues to increase rapidly in patients with diabetes. It is marked by myocardial remodeling, including fibrosis, hypertrophy, and cell death, leading to diastolic dysfunction with or without systolic dysfunction. Diabetic cardiomyopathy (DCM) is a distinct myocardial disease in the absence of coronary artery disease. DCM is partially induced by chronic systemic inflammation, underpinned by a hostile environment due to hyperglycemia, hyperlipidemia, hyperinsulinemia, and insulin resistance. The detrimental role of leukocytes, cytokines, and chemokines is evident in the diabetic heart, yet the precise role of inflammation as a cause or consequence of DCM remains incompletely understood. Here, we provide a concise review of the inflammatory signaling mechanisms contributing to the clinical complications of diabetes-associated HF. Overall, the impact of inflammation on the onset and development of DCM suggests the potential benefits of targeting inflammatory cascades to prevent DCM. This review is tailored to outline the known effects of the current antidiabetic drugs, anti-inflammatory therapies, and natural compounds on inflammation, which mitigate HF progression in diabetic populations.

Keywords: diabetes mellitus, inflammation, diabetic cardiomyopathy, treatment, heart failure

\section{INTRODUCTION}

Diabetes mellitus (DM) is present in $40 \%$ of heart failure (HF) patients and is concomitant with increased hospitalizations and risk of mortality (Tromp et al., 2020). Inflammation is widely recognized to play a crucial role in the pathogenesis of both HF with reduced and preserved ejection fraction. Systemic inflammation is frequently associated with abnormal cardiac structure and function in clinical studies (Suzuki et al., 2008; Sanders-van Wijk et al., 2020): nevertheless, conflicting outcomes have also been documented. In the Canakinumab Anti-Inflammatory Thrombosis Outcomes Study (CANTOS) (Ridker et al., 2012), anti-interleukin (IL)-1 $\beta$ treatment demonstrated a reduction in inflammatory markers in type $2 \mathrm{DM}(\mathrm{T} 2 \mathrm{DM})$; however, over a longer duration, it failed to reduce the risk of cardiovascular events (Tan et al., 2020). Therefore, an in-depth understanding of inflammatory molecular mechanisms is needed to outline potential treatment strategies for managing inflammation in diabetes. 


\section{IMMUNE SIGNALING IN THE HEART}

Myocardial injury instigated from myocarditis, myocardial infarction (MI), or metabolic stress triggers the innate and adaptive immune response in the heart. The innate response is a non-specific defense against cardiac injury, whereas the adaptive response is perpetuated by $\mathrm{B}$ and $\mathrm{T}$ cells designed to restore function (Mann, 2015). A pathological insult prompts the generation of pathogen-associated molecular patterns (PAMPs) or danger-associated molecular patterns (DAMPs) from cardiomyocytes, endothelial cells, fibroblasts, and leukocytes, depending on the stimuli (Castillo et al., 2020). Consequently, upon ligand binding, activation of DAMP/PAMP receptors and NLR family pyrin domain containing 3 (NLRP3) inflammasome pathways promote the production of proinflammatory cytokines, including tumor necrosis factor alpha (TNF $\alpha$ ), IL-1 $\beta$, IL-6, and IL-18, contributing to cardiac injury (Fairweather, 2007). The released inflammatory cytokines result in cardiac infiltration of leukocytes stimulating a restorative response in the heart. In various diseases, including diabetes, due to the lack of a resolution phase of the inflammatory state, myocardial inflammation contributes to pathological hypertrophic growth and leukocyte-mediated death of cardiomyocytes (Adamo et al., 2020). Besides, inflammatory cytokines also activate cardiac fibroblasts, inducing excessive interstitial fibrosis formation, leading to cardiac dysfunction (Franssen et al., 2016).

\section{MYOCARDIAL INFLAMMATION IN DIABETIC CARDIOMYOPATHY}

Hyperinsulinemia, insulin resistance, hyperglycemia, and hyperlipidemia induce diabetic cardiomyopathy (DCM) consequently resulting in HF (Nunes et al., 2012). DCM is characterized by cardiomyocyte death, hypertrophy, and fibrosis, and these aberrant events are a consequence of proinflammatory cascades occurring in different cardiac cell types (Tan et al., 2020). Diabetes-induced alterations in endothelial (Knapp et al., 2019) and cardiac muscle cells (Filardi et al., 2019) are reported to be one of the major causative elements in the onset and progression of DCM. Specifically, this mini review focuses on the inflammatory mechanisms implicated in cardiomyocytes in diabetes.

A positive feedback loop emanates from the stress-induced release of pro-inflammatory molecules such as TNF $\alpha$, IL$1 \beta$, and IL-6, accentuating leukocyte activation. This further activates the nuclear factor kappa-light-chain-enhancer of activated $\mathrm{B}$ cells (NF- $\mathrm{KB}$ ), a transcription factor with antioxidant function in the physiological state (Maier et al., 2012). Under pathological conditions, such as DCM, over-activation of NF$\kappa \mathrm{B}$ results in more prominent leukocyte recruitment to the heart (Bajpai and Tilley, 2018). Abundant leukocyte infiltration was exemplified in immunohistochemical staining of right atrial tissue from T2DM patients, showing increased $\mathrm{CD}^{+} 8^{+}$ macrophages compared to non-T2DM patients (Pierzynová et al., 2019). Moreover, diabetic stress can also induce hematopoiesis, resulting in increased circulating leukocytes (Nagareddy et al., 2013), fueling low-grade inflammation in the myocardium.

\section{The Different Roles of Leukocytes in Myocardial Inflammation}

Leukocyte activation and recruitment are responsible for diabetic cardiac injury. Neutrophils are first-responders and secrete various inflammatory mediators, such as cytokines, microparticles, and neutrophil extracellular traps (NETs), which induce sustained inflammation. Of note, an increased neutrophil/lymphocyte ratio was recently identified as an indicator associated with subclinical DCM ocurrence (Huang et al., 2020). Furthermore, elevated NET release following protein arginine deiminase upregulation in neutrophils (Wong et al., 2015) aggravates cardiac injury due to neutrophil-mediated cell death (NETosis) in diabetes (Fadini et al., 2016).

Macrophages engulf apoptotic/necrotic cardiomyocytes and debris to manage inflammation. However, this is impaired in diabetes due to reduced miR-126 expression and blunted MERTK function (Suresh Babu et al., 2016; Bajpai and Tilley, 2018). Moreover, macrophages are classified as pro-inflammatory (M1) and anti-inflammatory (M2), characterized by distinct sources of activation. The phenotypic balance between these subsets is necessary for the homeostasis of inflammatory responses. M1 macrophages arise from IFN- $\gamma$ and secrete IL-6, TNF $\alpha$, IL$1 \beta$, IL-12, and IL-23, whereas M2 macrophages are polarized by IL-4, IL-10, or IL-13 and express IL-10 and transforming growth factor beta (TGF $\beta$ ) (Van Linthout and Tschope, 2017). M1 macrophages are more predominant in diabetes, instigating insulin resistance by secreting resistin and prompting DCM progression (Lehrke et al., 2004); however, the M2 phenotype ameliorates cardiac dysfunction in DM (Jadhav et al., 2013). For instance, elevated M2 macrophage differentiation mitigated heart dysfunction following fibroblast growth factor (FGF)-9 (Singla et al., 2015) and bone morphogenetic protein 7 (BMP-7) (Urbina and Singla, 2014) treatment in diabetic rodents.

In the adaptive response, $\mathrm{T}$ helper (Th)-1 or Th-17 cells secrete pro-inflammatory cytokines, whereas $\mathrm{T}$ regulatory (Treg) cells secrete anti-inflammatory cytokines. In T2DM patients, skewed $\mathrm{Th} /$ Treg balance and elevated $\mathrm{T}$ cell homing contribute to cardiovascular complications by increasing cardiac hypertrophy and fibrosis (Zeng et al., 2012; Nevers et al., 2015; Bajpai and Tilley, 2018). Moreover, increased cytokines from systemic Th17 are associated with diastolic abnormality in diabetic children (Hoffman et al., 2013). Evidently, myocardial T-cell infiltration induces fibrosis in type $1 \mathrm{DM}$ (T1DM) mice via increased TGF $\beta$ expression, which is diminished by T-cell depletion (Abdullah et al., 2016). Lastly, B-cells maintain the bridge between innate and adaptive immunity via their antigen-specific response, and their presence contributes toward sustained inflammation in DCM. For instance, overexpression of allograft inflammatory factor (AIF-1), an anti-inflammatory cytokine, prevents streptozotocin (STZ)-induced cardiac dysfunction; on the contrary, AIF-1 downregulation is associated with elevated B-cell homing in the myocardium (Sarkar et al., 2018). The role 
of inflammatory cytokines, chemokines, and receptors in DCM is outlined in Table 1.

\section{NF-кB-Associated Signaling Pathways}

Overactivation of molecular pathways, such as NF- $\mathrm{B}$, signal transducer activating protein-1 (AP-1), c-Jun $\mathrm{NH}_{2}$-terminal kinase (JNK), and p38 mitogen-activated protein kinase (MAPK), favors the induction of a pro-inflammatory intramyocardial milieu in DM. NF- $\kappa \mathrm{B}$ pathway is the central converging point of inflammatory triggers stemming from several pathological stresses in diabetes, such as prolonged endoplasmic reticulum stress, hyperlipidemia, hyperglycemia, renin-angiotensinaldosterone system (RAAS) activation (Knapp et al., 2019), oxidative stress (Maier et al., 2012), and advanced glycation

TABLE 1 | The role of inflammatory cytokines, chemokines, and receptors in DCM.

\begin{tabular}{|c|c|c|c|c|c|}
\hline & Name & Role & Pre-clinical findings & Clinical findings & References \\
\hline \multirow[t]{6}{*}{ Cytokines } & $\mathrm{TNF} \alpha$ & $\begin{array}{l}\text { Pro- } \\
\text { inflammatory }\end{array}$ & $\begin{array}{l}\text { STZ-induced diabetic rats with } \\
\text { anti-TNF } \alpha \text { antibody treatment: } \\
\text { improved LV function, } \downarrow \text { IL- } 1 \beta \\
\text { expression, and } \downarrow \text { cardiac collagen } \\
\text { content. }\end{array}$ & $\begin{array}{l}\uparrow P l a s m a \text { TNF } \alpha \text { level is associated with } \\
\text { LV diastolic dysfunction in patients with } \\
\text { diabetes }\end{array}$ & $\begin{array}{l}\text { Westermann et al., } \\
\text { 2007a,b; Dinh et al., } 2009\end{array}$ \\
\hline & $\mathrm{IL}-18$ & $\begin{array}{l}\text { Pro- } \\
\text { inflammatory }\end{array}$ & $\begin{array}{l}\text { IL-18 KO mice fed with western diet: } \\
\text { preserved cardiac function and } \\
\downarrow \text { myocardial interstitial fibrosis }\end{array}$ & $\begin{array}{l}\text { 个IL-18 level is an independent predictor } \\
\text { of CV events in patients with metabolic } \\
\text { syndrome }\end{array}$ & $\begin{array}{l}\text { Troseid et al., 2009; } \\
\text { Carbone et al., } 2017\end{array}$ \\
\hline & IL-6 & $\begin{array}{l}\text { Pro- } \\
\text { inflammatory }\end{array}$ & $\begin{array}{l}\text { IL-6 KO mice with STZ-induced } \\
\text { diabetes: improved cardiac function } \\
\text { and } \downarrow \text { interstitial fibrosis; } \downarrow \text { TGF } \beta \text { and } \\
\uparrow m i R-29 \text { following high glucose }\end{array}$ & $\begin{array}{l}\uparrow P \text { lasma IL-6 level is associated with LV } \\
\text { diastolic dysfunction in patients with } \\
\text { diabetes }\end{array}$ & $\begin{array}{l}\text { Dinh et al., 2009; Zhang } \\
\text { et al., } 2016\end{array}$ \\
\hline & TGF $\beta$ & $\begin{array}{l}\text { Fibrogenic } \\
\text { mediator, pro- } \\
\text { inflammatory }\end{array}$ & $\begin{array}{l}\text { Db/db Smad3+/-mice: attenuated } \\
\text { cardiac diastolic dysfunction, } \\
\downarrow \text { hypertrophy, and fibrosis }\end{array}$ & $\begin{array}{l}\uparrow \text { Serum TGF } \beta \text { level is associated with } \\
\text { diastolic dysfunction in hypertensive } \\
\text { patients with metabolic syndrome }\end{array}$ & $\begin{array}{l}\text { Sciarretta et al., 2007; } \\
\text { Biernacka et al., } 2015\end{array}$ \\
\hline & $\mathrm{IL}-1 \beta$ & $\begin{array}{l}\text { Pro- } \\
\text { inflammatory }\end{array}$ & $\begin{array}{l}\text { STZ-induced diabetic mice: } \uparrow \text { cardiac } \\
\text { IL-1 } 1 \beta \text { expression, } \uparrow \text { cardiac collagen } \\
\text { content, and LV dysfunction; also } \\
\text { associated with cardiac arrhythmias }\end{array}$ & 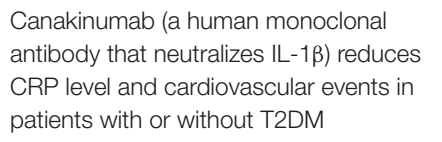 & $\begin{array}{l}\text { Westermann et al., } \\
\text { 2007a,b; Ridker et al., } \\
\text { 2012; Monnerat et al., } 2016\end{array}$ \\
\hline & HMGB1 & $\begin{array}{l}\text { Pro- } \\
\text { inflammatory }\end{array}$ & $\begin{array}{l}\text { Hyperglycemia induces } \uparrow \text { HMGB1 } \\
\text { expression and NF-кB activity in the } \\
\text { heart. STZ-induced diabetic mice with } \\
\text { HMGB1 silencing: ameliorated LV } \\
\text { dysfunction and remodeling }\end{array}$ & $\begin{array}{l}\uparrow \text { Serum HMGB1 in patients with } \\
\text { diabetes with HF; HMGB1 levels } \\
\text { inversely related to LV ejection fraction } \\
\text { in HF patients with or without diabetes }\end{array}$ & $\begin{array}{l}\text { Volz et al., 2010; Wang } \\
\text { et al., 2011; Wang W. et al., } \\
2014\end{array}$ \\
\hline \multirow[t]{2}{*}{ Chemokines } & MCP-1 & $\begin{array}{l}\text { Stimulates } \\
\text { monocytes and } \\
\text { macrophages }\end{array}$ & $\begin{array}{l}\text { MCP-1 induces glucose-mediated cell } \\
\text { death in isolated cardiomyocytes via } \\
\text { oxidative and endoplasmic-reticulum } \\
\text { stress }\end{array}$ & $\begin{array}{l}\uparrow P l a s m a \text { MCP- } 1 \text { level in T2DM patients } \\
\text { associated with CV-associated } \\
\text { mortality }\end{array}$ & $\begin{array}{l}\text { Piemonti et al., 2009; } \\
\text { Younce et al., } 2010\end{array}$ \\
\hline & MMP-2 & $\begin{array}{l}\text { ECM } \\
\text { degradation }\end{array}$ & $\begin{array}{l}\text { STZ-induced diabetic mice: } \downarrow \text { MMP-2 } \\
\text { and } \uparrow S m a d 7 \text { expression contribute to } \\
\text { cardiac fibrosis }\end{array}$ & $\begin{array}{l}\uparrow \text { Serum MMP-2 level in patients with } \\
\text { and without diabetes; not an } \\
\text { independent risk factor }\end{array}$ & $\begin{array}{l}\text { Van Linthout et al., 2008; } \\
\text { Kobusiak-Prokopowicz } \\
\text { et al., } 2018\end{array}$ \\
\hline \multirow[t]{3}{*}{ Receptors } & CCR2 & $\begin{array}{l}\text { Macrophage } \\
\text { recruitment }\end{array}$ & $\begin{array}{l}\text { CCR2 KO in STZ-induced diabetic and } \\
\text { CCR2 inhibition in db/db mice: } \\
\text { improved cardiac dysfunction, } \\
\downarrow \text { oxidative stress, and M1 macrophage } \\
\text { infiltration along with reversing } \\
\text { hyperglycemia }\end{array}$ & $\begin{array}{l}\uparrow C C R 2 \text { expression of circulating } \\
\text { monocytes associated with } \uparrow \text { arterial } \\
\text { wall inflammation in patients with high } \\
\text { risk of CV event, including patients with } \\
\text { diabetes }\end{array}$ & $\begin{array}{l}\text { Verweij et al., 2018; Tan } \\
\text { et al., } 2019\end{array}$ \\
\hline & RAGE & $\begin{array}{l}\text { Pro- } \\
\text { inflammatory }\end{array}$ & $\begin{array}{l}\text { RAGE KO mice fed a high-fat diet: } \\
\downarrow \text { Cardiac hypertrophy, inflammation, } \\
\text { and collagen accumulation due to } \\
\downarrow \text { oxidative stress }\end{array}$ & $\begin{array}{l}\uparrow \text { Serum cRAGE and HMGB1 levels in } \\
\text { diabetic HF patients vs. non-diabetic } \\
\text { HF patients; associated with } \\
\text { development and severity of HF }\end{array}$ & $\begin{array}{l}\text { Tikellis et al., 2008; Wang } \\
\text { et al., } 2011\end{array}$ \\
\hline & $\operatorname{TLR}(4,2)$ & $\begin{array}{l}\text { Pro- } \\
\text { inflammatory }\end{array}$ & $\begin{array}{l}\text { STZ-induced diabetic mice with TLR4 } \\
\text { silencing: } \downarrow \text { fibrosis and expression of } \\
\text { TGF } \beta \text { and adhesion molecules, } \\
\text { preserves cardiac contractility } \\
\text { Stimulation of TLR- } 2 \text { in } \mathrm{HL}-1 \\
\text { cardiomyocytes } \uparrow N F-\kappa B \text { activation, } \\
\text { thereby decreasing contractility }\end{array}$ & $\begin{array}{l}\text { TLR4 mutation confers protection } \\
\text { against T2DM, but not against ischemic } \\
\text { heart diseases in diabetic and } \\
\text { non-diabetic patients }\end{array}$ & $\begin{array}{l}\text { Boyd et al., 2006; } \\
\text { Manolakis et al., } 2011 ; \\
\text { Zhang et al., } 2020\end{array}$ \\
\hline
\end{tabular}

CCR2, C-C motif chemokine receptor 2; CRAGE, cleaved RAGE; CRP, C-reactive protein; CV, cardiovascular; ECM, extracellular matrix; HF, heart failure; HMGB1, high-

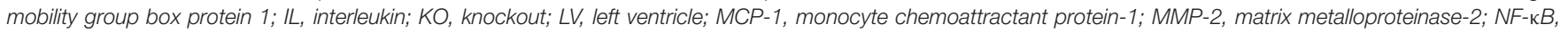

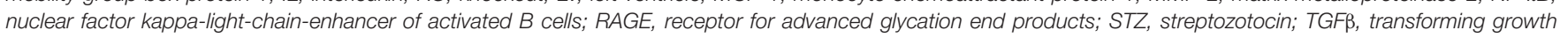
factor beta; TLR, Toll-like receptor; TNF $\alpha$, tumor necrosis factor alpha; T1DM, type 1 diabetes mellitus; T2DM, type 2 diabetes mellitus; $\uparrow$, increased; $\downarrow$, decreased. 
end products (AGEs) (Palomer et al., 2013). NF- $\kappa$ B activation contributes to myocardial fibrosis, hypertrophy, apoptosis, and ventricular dysfunction (Frati et al., 2017). On the other hand, NF- $\kappa$ B inhibition by I $\kappa$ B- $\alpha$ overexpression showed reduced RAAS activation and preserved calcium handling in STZinduced diabetic heart (Thomas et al., 2014). ROS production in response to hyperlipidemia, hyperglycemia, and mitochondrial dysfunction also triggers $N F-\kappa B$ signaling in the diabetic heart via degradation of IКB- $\alpha$ (Baker et al., 2011) and downregulation of nuclear factor erythroid 2-related factor 2 (Nrf-2) following Erk1/2 activation (Tan et al., 2011). Moreover, elevated DAMP release from isolated cardiomyocytes, macrophages, fibroblasts, and endothelial cells under diabetic conditions (Frati et al., 2017) results in NF- $\kappa \mathrm{B}$ activation accompanied by increase in cytokines (Wang W. et al., 2014). In T1DM, NF- $\kappa$ B activity is increased following hyperglycemia, oxidative stress-induced JNK phosphorylation (Pan et al., 2014), and reduction in insulininduced GSK-3 $\beta$ phosphorylation (Wang et al., 2009; Ge et al., 2019), thereby augmenting lipid accumulation, inflammation, and fibrosis in the heart. Furthermore, high glucose-mediated post-translational modifications in the p65 subunit of NF- $\kappa$ B alter its activity. For example, p65 O-GlcNAcylation enhances NF- $\kappa \mathrm{B}$ activation by decreasing its binding to I $\mathrm{B}-\alpha$ (Yang et al., 2008); on the contrary, sirtuin 1-mediated p65 deacetylation at a lysine site (Lys310) suppresses NF- $\mathrm{B}$ transcriptional activity (Planavila et al., 2011), thereby modulating cardiac inflammation.

\section{Roles of the Receptor for AGE- and TLR-Mediated Cardiac Inflammation}

Advanced glycation end products are generated from nonenzymatic glycation and oxidation of proteins or lipids in response to metabolic stress (Ahmed, 2005). The receptor for AGEs (RAGEs) binds multiple ligands, including AGEs and DAMPs (Ramasamy et al., 2011), contributing to the generation of pro-inflammatory cytokines and oxidative stress (Koyama et al., 2008). Elevated AGE formation is correlated with collagen accumulation, myocardial fibrosis, impaired calcium homeostasis, and mitochondrial dysfunction in the diabetic heart (Bidasee et al., 2003). Moreover, Toll-like receptors (TLRs) are essential to activate innate immunity by responding to PAMPs or DAMPs and participate in adaptive immunity by regulating the activation of circulating lymphocytes (Mann, 2011). Increased free fatty acid (FFA) levels in diabetes promote inflammation via AGE production and activation of TLR4 (Kim et al., 2007) and protein kinase C (PKC) (Itani et al., 2002), resulting in increased NF- $\kappa \mathrm{B}$ activity. Furthermore, TLR4-mediated inflammatory signaling is apparent in several animal models of T1DM (Tan et al., 2020), such that genetic ablation of TLR4 reduced cardiac inflammation and improved cardiac function (Dong et al., 2012). The hetero-dimerization of RAGE and TLR stimulated pro-IL$1 \beta$ and pro-IL-18, whereas impediment of RAGE reduced the cardiac inflammatory response in $d b / d b$ mice and improved diastolic function (Nielsen et al., 2009). Interestingly, the interaction of AGEs with RAGE also triggers NF- $\kappa$ B activation, further transcriptionally regulating RAGE expression in a positive feedback loop (Gao et al., 2008) and aggravating cardiac inflammation. Hyperglycemia-induced AGEs can also directly bind to myeloid differentiation 2 (MD2)-TLR4 receptor complex, initiating inflammatory pathways and consequent myocardial injury, contributing to cardiac dysfunction in type 1 and type 2 diabetic mice (Wang et al., 2020).

\section{Involvement of NLRP3 Inflammasome in Cardiac Inflammation}

Inflammasome stimulation is a two-step process requiring priming by inflammatory stimuli. The first step is NF- $\mathrm{B}$ transcriptional upregulation of NLRP3 and pro-IL-1 $\beta$. The second step involves DAMP-mediated inflammasome assembly, causing oxidative stress and inflammation-induced programmed cell death, also known as pyroptosis (Luo et al., 2017). In diabetes, mitochondrial damage has been detected as an important contributor to inflammasome assembly through the release of mitochondrial DNA and ROS. Moreover, excessive cytokines, in turn, exacerbate mitochondrial dysfunction in a positive feedback loop (Luo et al., 2014; Schilling, 2015). Interestingly, inflammasome expression is markedly increased in rodent diabetic hearts via oxidative stress-dependent thioredoxininteracting/inhibiting protein (TXNIP) activation, showing elevated caspase-1 and IL-1 $\beta$ activation (Stienstra et al., 2011). This pro-inflammatory mechanism is absent in high-fat dietfed mice with NLRP3 deficiency (Luo et al., 2014). NLRP3 inflammasome cleaves caspase- 1 from pro-caspase 1 , which is involved in the maturation of inflammatory cytokines, such as IL$1 \beta$, and pyroptosis-triggered fibrosis in DCM (Peiró et al., 2017). IL- $1 \beta$ triggers multiple signaling pathways through its interaction with the IL- $1 \beta$ receptor on cardiomyocytes in diabetic conditions (Dinarello, 2009). For instance, in T1DM, IL-1 $\beta$ promoted $\mathrm{C} / \mathrm{EBP}$ homologous protein (CHOP)-dependent cell death and cardiac dysfunction, which is attenuated by the administration of recombinant IL-1 receptor antagonist (Liu et al., 2015). Similarly, pharmacological inhibition of caspase- 1 attenuated inflammation and cardiac dysfunction in STZ-injected rats (Westermann et al., 2007a). The schematic representation of inflammatory signaling in DCM is shown in Figure 1.

\section{THERAPEUTIC STRATEGIES FOR PREVENTION OF DCM BY TARGETING INFLAMMATION}

Given the intimate association between inflammation and DCM, therapeutic interventions targeting myocardial inflammation are essential to mitigate the onset and progression of HF in patients with DM. First, the inflammatory cascade instigators, such as hyperglycemia, hyperlipidemia, oxidative stress, and insulin resistance, continuously aggravate inflammation following the onset of DCM. Therefore, managing these instigators could aid to regulate inflammation and prevent $\mathrm{HF}$ development. Second, the inflammatory signaling processes can be modulated directly to prevent cardiac dysfunction in diabetes. For instance, suppression of inflammation is achieved by inhibition of pro-inflammatory cytokines, chemokines, and DAMPs; 


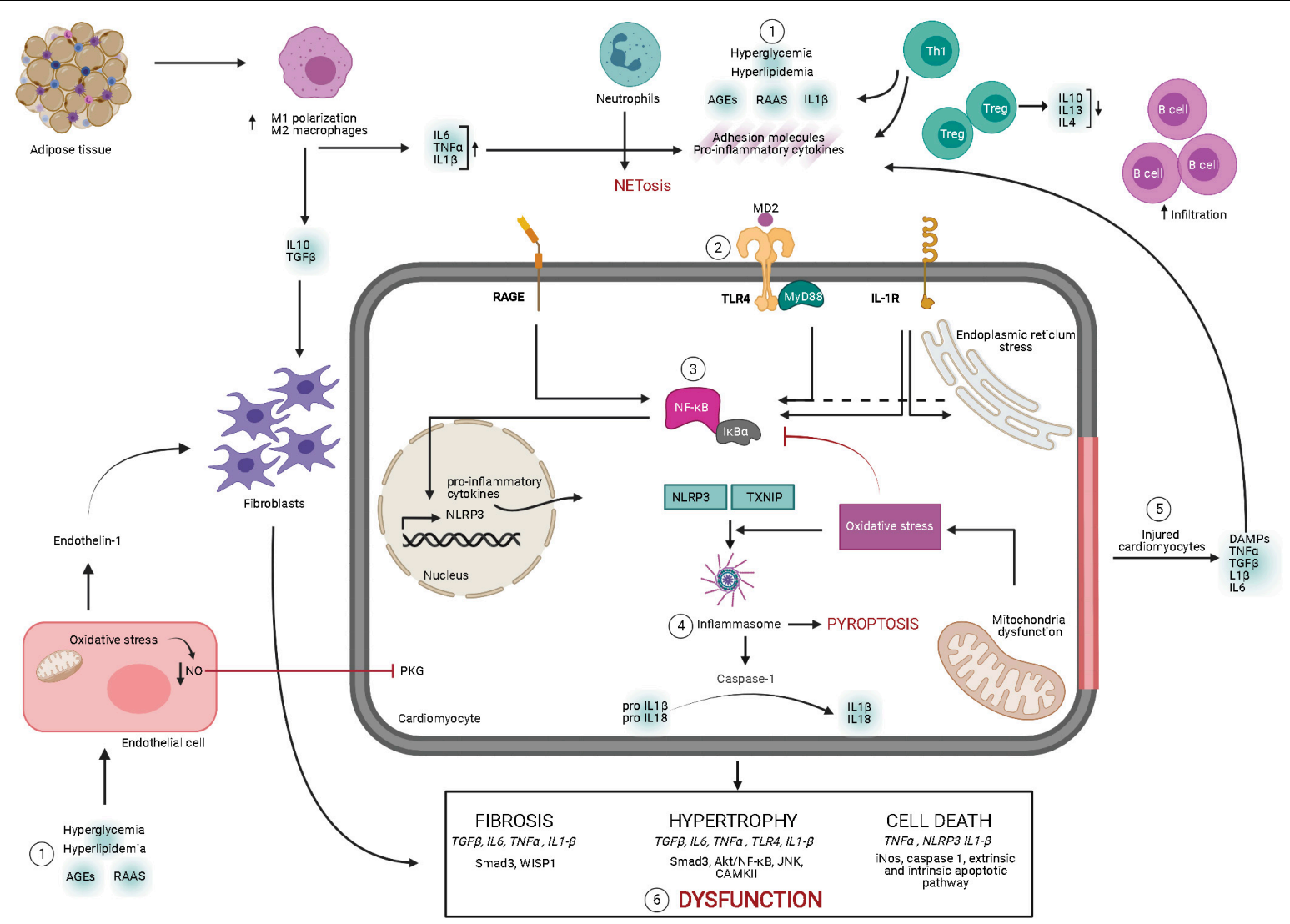

FIGURE 1 | Overview of signaling mechanisms underlying myocardial inflammation in diabetes mellitus. Diabetic milieu comprises of elevated leukocyte homing in the myocardium. Pathological stresses such as hyperglycemia, hyperlipidemia, elevated RAAS, and AGEs induce secretion of pro-inflammatory molecules, adhesion molecules, and DAMPs from the leukocytes. Moreover, these instigators also induce ROS-mediated endothelial dysfunction contributing to cardiac remodeling. Secreted pro-inflammatory cytokines bind to the receptors, such as TLR-4-MyD88 complex, RAGE, and IL-1R, and initiate their intracellular signaling pathways. These pathways activate NF-kB, resulting in transcriptional upregulation of inflammatory cytokines and NLRP3 inflammasome. Following NF-kB activation and oxidative stress, inflammasome assembly leads to maturation of IL-1 $\beta$ and IL-18, along with induction of pyroptosis. Meanwhile, stressed or injured cardiomyocytes release pro-inflammatory cytokines and DAMPs, contributing to aggravated inflammatory cascades. Chronic inflammatory cytokine-induced intracellular response leads to pathological cardiac remodeling and cardiac dysfunction. AGE, advanced end glycation products; DAMP, danger-associated molecular pattern; IL, interleukin; IL-1R, interleukin 1 beta receptor; MD2, myeloid differentiation 2; MyD88, myeloid differentiation primary response 88; NLRP3, NLR family pyrin domain containing 3; NETosis, neutrophil-mediated cell death; NF-kB, nuclear factor kappa-light-chain-enhancer of activated B cells; NO, nitric oxide; PKG, protein kinase G; RAAS, renin-angiotensin-aldosterone system; RAGE, receptor for AGEs; TGF $\beta$, transforming growth factor beta; TLR-4, Toll-like receptor 4; TNF $\alpha$, tumor necrosis factor alpha; TXNIP, thioredoxin-interacting/inhibiting protein (created with Biorender.com).

macrophage polarization toward M2 phenotype; moderation of inflammasome activity; and restraint of leukocyte recruitment.

\section{Anti-diabetic Drugs \\ Insulin Sensitizers}

Current anti-diabetic therapies improve glycemic control and insulin sensitivity in patients with diabetes and thereby indirectly manage systemic and myocardial inflammation (Reis et al., 2012). Abrogation of cardiac insulin resistance is shown to mitigate inflammatory cardiac dysfunction by decreased production of pro-inflammatory adhesion molecules, C-reactive protein (CRP), and IL-6 (Dandona et al., 2009; Al-Huseini et al., 2019). Metformin, the first-line anti-diabetic drug in clinics, promotes glucose homeostasis and improves impaired heart function in patients with diabetes by blocking proinflammatory markers such as CCL11 (Dludla et al., 2020).
Notably, metformin also exhibits its anti-inflammatory effects by inhibiting NF- $\mathrm{BB}$ (Hattori et al., 2006), reducing CRP production from vessel walls (Li et al., 2009), and blocking monocyte differentiation into macrophages (Vasamsetti et al., 2015), irrespective of diabetic status. However, the mechanisms of metformin's anti-inflammatory action in DCM require further attention.

Peroxisome proliferator-activated receptor- $\gamma(\operatorname{PPAR} \gamma)$ is a member of the PPAR nuclear hormone receptor superfamily, and its activation promotes pleiotropic biological effects such as reduced serum glucose and regulated cardiac metabolism in DM (Liu et al., 2016). The use of a PPAR $\gamma$ agonist, rosiglitazone, has shown anti-inflammatory effects in T2DM patients resulting in improved diastolic function (von Bibra et al., 2008). In contrast, other insulin-sensitizing agents and thiazolidinediones present a neutral or deleterious effect on cardiac structure and 
function in T2DM patients (Naka et al., 2010), making their anti-inflammatory role unsubstantiated in DCM.

\section{Sodium Glucose Co-transporter 2 Inhibitors}

Sodium-glucose co-transporter 2 (SGLT2) inhibitors (SGLT2is) promote glycosuria by inhibiting SGLT2 in nephrons and thereby improve glycemic control (Kenny and Abel, 2019). More recently, SGLT2is have gained attention due to their ability to reduce HF progression in patients irrelevant of their diabetic status (Natali et al., 2017; Zannad et al., 2020). In diabetic patients, SGLT2is likely potentiate their cardioprotective effects through multiple actions, including amelioration of inflammation (Scheen, 2020). SGLT2is are able to reduce endothelial inflammation in T1DM mice (Zhou et al., 2018), decrease cardiac macrophage infiltration in pre-diabetic rats (Kusaka et al., 2016), downregulate cardiac cytokine expression (Radlinger et al., 2020), and attenuate inflammasome activation (Ye et al., 2017), all of which result in repressed secretion of pro-inflammatory cytokines and improved cardiac function in T2DM genetic models (Aragon-Herrera et al., 2019). Furthermore, STZ-injected rats displayed decreased cardiac expression of NLRP3, caspase-1, and IL- $1 \beta$ following SGLT2i (empagliflozin) treatment (Trang et al., 2021). SGLT2is are suggested to alleviate cardiac inflammation independent of their anti-hyperglycemic effect observed via reducing TLR4 and TNF $\alpha$ in angiotensin-II-induced cardiomyopathy in $d b / d b$ mice (Arow et al., 2020). Taken together, these studies suggest that SGLT2is exert anti-inflammatory effects that positively influence cardiac function in rodent models of DM; however, the mechanistic link remains poorly defined. Of note, the majority of data have been obtained from T1DM pre-clinical models; therefore, the role of anti-diabetic drugs on cardiac inflammation in T2DM needs further exploration.

\section{Dipeptidyl Peptidase 4 Inhibition and Glucagon-Like Peptide-1 Agonists}

Dipeptidyl peptidase 4 (DPP-4) inhibitors increase incretin hormone, glucagon-like peptide 1 (GLP-1) levels exerting beneficial actions on glucose homeostasis and insulin sensitivity. Both DPP-4 inhibitors and GLP-1 agonists are used in clinics as anti-diabetic therapies; however, their role in protecting against cardiac dysfunction in diabetes remains uncertain. Linagliptin, a DPP-4 inhibitor, prevented cardiac dysfunction by attenuating inflammasome activation in $d b / d b$ mice following MI. Moreover, in vitro experiments displayed a lower TLR4 in human cardiomyocytes and cardiofibroblasts following highglucose stimulation and linagliptin treatment. Interestingly, this protective mechanism was absent following exenatide exposure, which is a GLP-1 analog, suggesting that DPP-4 inhibitors might have a direct anti-inflammatory effect regardless of GLP-1 levels (Birnbaum et al., 2019). Contrastingly, exendin4, another GLP-1 analog, displayed cardioprotective effects via enhancing AMP-activated kinase (AMPK) phosphorylation following hyperglycemia in high-fat diet-fed mice (Wei et al., 2019). Also, DPP-4 inhibition reduces monocyte recruitment to the myocardium (Shah et al., 2011) and suppresses the activation of inflammatory proteases, thereafter preventing adverse cardiac remodeling (Kolpakov et al., 2019) in experimental models of
DCM (Zhong et al., 2015). On the contrary, DPP-4 inhibitors also increase endogenous stromal cell-derived factor (SDF) (Packer, 2018), a chemokine emanating from adipose tissue, which promotes inflammation-induced fibrosis in the diabetic myocardium, albeit diminished by SDF receptor (CXCR4) antagonism (Chu et al., 2015). These conflicting results require further investigation to establish their anti-inflammatory potentials in DCM.

\section{Anti-inflammatory Therapies}

Direct immune modulation can also be beneficial in the management of DM's chronic inflammatory state. In T1DM mice, administration of FTY720 inhibited cardiac fibrosis by regulating T-cell infiltration (Abdullah et al., 2016). Nonetheless, targeting a single inflammatory mechanism might provoke a secondary compensatory inflammatory response. For instance, anti-TNF $\alpha$ therapy (Chung et al., 2003) or IL1 $\beta$ suppression (Torre-Amione et al., 2008) aggravated clinical outcomes in patients administered with the highest doses, owing to their inadvertent or unknown effects such as intrusion of homeostatic inflammation and agonist activity of the antagonists (Mann, 2015).

Immunosuppressants such as methotrexate improved myocardial inflammation via reduced expression of macrophages in T1DM rats (Cavalcante Maranhao et al., 2017). Methotrexate also reduced cardiovascular events in patients, though research is limited to patients with rheumatoid arthritis (Baghdadi, 2020). Lastly, adjunct anti-inflammatory therapies, such as statins and canakinumab, are suggested to reduce the burden of DCM, possibly by alleviating IL1 $\beta$-dependent insulin resistance in metabolic disorders (Gao and Ye, 2012; Liberale et al., 2019). Overall, the current anti-inflammatory therapies seem promising yet require further exploration in the setting of DCM.

\section{Natural Compounds}

The study of anti-inflammatory effects of natural compounds in DCM is on the rise in pre-clinical and clinical research. An adequate diet has demonstrated a significant implication for maintaining cardiac function in patients with diabetes (Kozlowska, 2017; Allen et al., 2019). For instance, quercetin, a flavonoid, lowers systolic blood pressure in type 2 diabetic women without a positive effect on inflammatory biomarkers contradictory to pre-clinical data (Rivera et al., 2008; Roslan et al., 2017), possibly due to small sample size recruitment (Zahedi et al., 2013). However, administration of curcumin, a turmeric root extract, lowers circulating pro-inflammatory markers in patients with diabetes-induced organ dysfunction (Gupta et al., 2013). Yet, its specific role in DCM patients remains to be elucidated.

Leukocyte infiltration is one of the early inflammatory events in DCM before the advent of clinical outcomes. There is compelling evidence that certain natural compounds such as isoliquiritigenin (ISL) and ginger extract can reduce macrophage infiltration via suppressed MAPK signaling (Gu et al., 2020) and reduced TGF $\beta$ expression (Abdi et al., 2021), respectively, in T1DM. However, only ISL preserved cardiac function; the ginger extract majorly prevented myocardial structural damage. 
Certain natural compounds can ameliorate cardiac inflammation by directly modulating inflammatory responses. Probiotics, fungi, and medicinal plants exert an antiinflammatory action via downregulation of TLR4 expression (Chiang et al., 2021) and reduction of IL-1 $\beta$, TNF $\alpha$, MCP-1, and TGF $\beta$ (Wang et al., 2018; Shaher et al., 2020), subsequently preserving cardiac structure and function in T1DM rodents. Moreover, hederagenin, a plant extract, improves cardiac function by diminishing secretion of pro-inflammatory cytokines and decreasing NF- $\kappa \mathrm{B}$ transcriptional activity in $d b / d b$ mice (Li Y. et al., 2019). Also, PPAR $\gamma$ agonism by crocin, a carotenoid compound found in saffron, reduces TNF $\alpha$ and IL- 6 levels in diabetic rats following MI (Badavi et al., 2020). Similar antiinflammatory effects were observed in clinical trials involving type 2 patients, which is likely due to the alleviation of insulin resistance and restoration of glycemic control; however, further research is warranted (Behrouz et al., 2020).

The anti-inflammatory effects of natural compounds are multifold, though varied among cell types. For instance, syringaresinol (SYR), a cereal extract, suppressed both Kelchlike ECH-associated protein 1 (KEAP1)/Nrf2 and TGF $\beta /$ Smad pathway in neonatal cardiomyocytes, resulting in reduced cardiac macrophage density and improved cardiac function ( $\mathrm{Li}$ et al., 2020). Interestingly, SYR can also downregulate NF$\kappa \mathrm{B}$ activation via $\mathrm{p} 38$ stimulation in macrophages in vitro, thereby reducing inflammation indirectly (Bajpai et al., 2018). Some pleiotropic agents, such as curcumin (Zheng et al., 2018), sophocarpine (Zou et al., 2019), and luteolin (Li L. et al., 2019), ameliorate DCM by suppressing NF- $\kappa B$ signaling pathway and the subsequent secretion of pro-inflammatory molecules. In addition, curcumin analogs, C66 and J17, have both direct and indirect anti-inflammatory roles. C66 lowers serum and cardiac triglyceride levels and inhibits JNK signaling (Wang Y. et al., 2014). Moreover, J17 protects diabetic mice and $\mathrm{H} 9 \mathrm{c} 2$ cardiomyoblasts against high glucoseinduced inflammation by inhibition of p38 signaling pathway (Chen et al., 2017). Interestingly, both SYR-activated p38 in macrophages (Bajpai et al., 2018) and curcumin-inhibited p38 in cardiomyocytes modulate cardiac inflammation in diabetes.

\section{REFERENCES}

Abdi, T., Mahmoudabady, M., Marzouni, H. Z., Niazmand, S., and Khazaei, M. (2021). Ginger (Zingiber Officinale Roscoe) extract protects the heart against inflammation and fibrosis in diabetic rats. Can. J. Diabetes 43, 220-227. doi: 10.1016/j.jcjd.2020.08.102

Abdullah, C. S., Li, Z., Wang, X., and Jin, Z. Q. (2016). Depletion of T lymphocytes ameliorates cardiac fibrosis in streptozotocin-induced diabetic cardiomyopathy. Int. Immunopharmacol. 39, 251-264. doi: 10.1016/j.intimp. 2016.07.027

Adamo, L., Rocha-Resende, C., Prabhu, S. D., and Mann, D. L. (2020). Reappraising the role of inflammation in heart failure. Nat. Rev. Cardiol. 17, 269-285. doi: 10.1038/s41569-019-0315-x

Ahmed, N. (2005). Advanced glycation endproducts-role in pathology of diabetic complications. Diabetes Res. Clin. Pract. 67, 3-21. doi: 10.1016/j.diabres.2004. 09.004

Al-Huseini, I., Harada, M., Nishi, K., Nguyen-Tien, D., Kimura, T., and Ashida, N. (2019). Improvement of insulin signalling rescues inflammatory cardiac dysfunction. Sci. Rep. 9:14801. doi: 10.1038/s41598-019-51304-8
These opposing mechanistic effects encapsulate the complexity and challenge of targeting inflammatory mechanisms in DCM. Overall, these natural compounds effectuate anti-inflammatory properties in the heart, yet their mechanistic role in different cardiac cell types, long-term implications, and clinical relevance remain undetermined.

\section{CONCLUSION}

Myocardial inflammation is a significant causative factor in diabetes-induced cardiac dysfunction. Positive feedback loops between the defective cardiomyocytes and harmful inflammatory responses lead to excessive pro-inflammatory cytokines and the recruitment of inflammatory cells in the myocardium, resulting in cardiac dysfunction. Clinical and pre-clinical studies demonstrate that mitigation of myocardial inflammation is closely linked to preserved cardiac function. Therefore, further efforts should be made to better understand the molecular mechanisms whereby cardiac inflammation contributes to DCM progression. Furthermore, a notable amount of research is still required to evaluate and develop therapeutic strategies targeting myocardial inflammation in diabetes.

\section{AUTHOR CONTRIBUTIONS}

NK and YG collected the references and generated the table. $\mathrm{NK}, \mathrm{YG}, \mathrm{RR}$, and AR-V generated the figure and drafted and proofread the manuscript. NK and WL designed the manuscript. All authors contributed to the article and approved the submitted version.

\section{FUNDING}

This work was supported by grants FS/15/16/31477, FS/18/73/33973, PG/19/66/34600, and FS/19/70/34650 to WL from the British Heart Foundation.

Allen, K. E., Gumber, D., and Ostfeld, R. J. (2019). Heart failure and a plant-based diet. A case-report and literature review. Front. Nutr. 6:82. doi: 10.3389/fnut. 2019.00082

Aragon-Herrera, A., Feijoo-Bandin, S., Otero Santiago, M., Barral, L., CamposToimil, M., Gil-Longo, J., et al. (2019). Empagliflozin reduces the levels of CD36 and cardiotoxic lipids while improving autophagy in the hearts of Zucker diabetic fatty rats. Biochem. Pharmacol. 170:113677. doi: 10.1016/j.bcp.2019. 113677

Arow, M., Waldman, M., Yadin, D., Nudelman, V., Shainberg, A., Abraham, N. G., et al. (2020). Sodium-glucose cotransporter 2 inhibitor Dapagliflozin attenuates diabetic cardiomyopathy. Cardiovasc. Diabetol. 19:7. doi: 10.1186/s12933-0190980-4

Badavi, M., Mard, S. A., Dianat, M., and Dashtbozorgi, N. (2020). Crocin attenuates oxidative stress and inflammation in myocardial infarction induced by isoprenaline via PPARgamma activation in diabetic rats. J. Diabetes Metab. Disord. 19, 1517-1525. doi: 10.1007/s40200-020-00686-y

Baghdadi, L. R. (2020). Effect of methotrexate use on the development of type 2 diabetes in rheumatoid arthritis patients: A systematic review and metaanalysis. PLoS One 15:e235637. doi: 10.1371/journal.pone.0235637 
Bajpai, A., and Tilley, D. G. (2018). The role of leukocytes in diabetic cardiomyopathy. Front. Physiol. 9:1547. doi: 10.3389/fphys.2018.01547

Bajpai, V. K., Alam, M. B., Quan, K. T., Ju, M. K., Majumder, R., Shukla, S., et al. (2018). Attenuation of inflammatory responses by (+)-syringaresinol via MAPKinase-mediated suppression of NF-kappaB signaling in vitro and in vivo. Sci. Rep. 8:9216. doi: 10.1038/s41598-018-27585-w

Baker, R. G., Hayden, M. S., and Ghosh, S. (2011). NF-kappaB, inflammation, and metabolic disease. Cell Metabol. 13, 11-22. doi: 10.1016/j.cmet.2010.12.008

Behrouz, V., Dastkhosh, A., Hedayati, M., Sedaghat, M., Sharafkhah, M., and Sohrab, G. (2020). The effect of crocin supplementation on glycemic control, insulin resistance and active AMPK levels in patients with type 2 diabetes: a pilot study. Diabetol. Metab. Syndr. 12:59. doi: 10.1186/s13098-020-00568-6

Bidasee, K. R., Nallani, K., Yu, Y., Cocklin, R. R., Zhang, Y., Wang, M., et al. (2003). Chronic diabetes increases advanced glycation end products on cardiac ryanodine receptors/calcium-release channels. Diabetes 52, 1825-1836. doi: 10. 2337/diabetes.52.7.1825

Biernacka, A., Cavalera, M., Wang, J., Russo, I., Shinde, A., Kong, P., et al. (2015). Smad3 signaling promotes fibrosis while preserving cardiac and aortic geometry in obese diabetic mice. Circ. Heart Failure 8, 788-798. doi: 10.1161/ circheartfailure.114.001963

Birnbaum, Y., Tran, D., Bajaj, M., and Ye, Y. (2019). DPP-4 inhibition by linagliptin prevents cardiac dysfunction and inflammation by targeting the Nlrp3/ASC inflammasome. Basic Res. Cardiol. 114:35. doi: 10.1007/s00395-019-0743-0

Boyd, J. H., Mathur, S., Wang, Y., Bateman, R. M., and Walley, K. R. (2006). Tolllike receptor stimulation in cardiomyoctes decreases contractility and initiates an NF-kappaB dependent inflammatory response. Cardiovasc. Res. 72, 384-393. doi: 10.1016/j.cardiores.2006.09.011

Carbone, S., Lee, P. J., Mauro, A. G., Mezzaroma, E., Buzzetti, R., Van Tassell, B., et al. (2017). Interleukin-18 mediates cardiac dysfunction induced by western diet independent of obesity and hyperglycemia in the mouse. Nutr. Diabetes 7:e258. doi: 10.1038/nutd.2017.1

Castillo, E. C., Vázquez-Garza, E., Yee-Trejo, D., García-Rivas, G., and TorreAmione, G. (2020). What is the role of the inflammation in the pathogenesis of heart failure? Curr. Cardiol. Rep. 22, 1-15.

Cavalcante Maranhao, R., França Marques, A., Guido, M. C., Rufo Tavares, E., Lima Bispo, D., Dantas Tavares de Melo, M., et al. (2017). Effects of treatment with methotrexate associated to lipid nanoparticles on diabetic cardiomyopathy in rats. Atherosclerosis 263:e48. doi: 10.1016/j.atherosclerosis.2017.06.165

Chen, H., Yang, X., Lu, K., Lu, C., Zhao, Y., Zheng, S., et al. (2017). Inhibition of high glucose-induced inflammation and fibrosis by a novel curcumin derivative prevents renal and heart injury in diabetic mice. Toxicol. Lett. 278, 48-58. doi: 10.1016/j.toxlet.2017.07.212

Chiang, C. J., Tsai, B. C., Lu, T. L., Chao, Y. P., Day, C. H., Ho, T. J., et al. (2021). Diabetes-induced cardiomyopathy is ameliorated by heat-killed Lactobacillus reuteri GMNL-263 in diabetic rats via the repression of the toll-like receptor 4 pathway. Eur. J. Nutr. 2021:e02474. doi: 10.1007/s00394-020-02474-z

Chu, P. Y., Walder, K., Horlock, D., Williams, D., Nelson, E., Byrne, M., et al. (2015). CXCR4 antagonism attenuates the development of diabetic cardiac fibrosis. PLoS One 10:e0133616. doi: 10.1371/journal.pone.0133616

Chung, E. S., Packer, M., Lo, K. H., Fasanmade, A. A., Willerson, J. T., and Anti, T. N. F. T. A. C. H. F. I. (2003). Randomized, double-blind, placebocontrolled, pilot trial of infliximab, a chimeric monoclonal antibody to tumor necrosis factor-alpha, in patients with moderate-to-severe heart failure: results of the anti-TNF Therapy Against Congestive Heart Failure (ATTACH) trial. Circulation 107, 3133-3140. doi: 10.1161/01.CIR.0000077913.60364.D2

Dandona, P., Chaudhuri, A., Ghanim, H., and Mohanty, P. (2009). Insulin as an anti-inflammatory and antiatherogenic modulator. J. Am. Coll. Cardiol. 53, S14-S20. doi: 10.1016/j.jacc.2008.10.038

Dinarello, C. A. (2009). Immunological and inflammatory functions of the interleukin-1 family. Ann. Rev. Immunol. 27, 519-550. doi: 10.1146/annurev. immunol.021908.132612

Dinh, W., Füth, R., Nickl, W., Krahn, T., Ellinghaus, P., Scheffold, T., et al. (2009). Elevated plasma levels of TNF-alpha and interleukin-6 in patients with diastolic dysfunction and glucose metabolism disorders. Cardiovas. Diabetol. 8, 1-7.

Dludla, P. V., Nyambuya, T. M., Johnson, R., Silvestri, S., Orlando, P., MazibukoMbeje, S. E., et al. (2020). Metformin and heart failure-related outcomes in patients with or without diabetes: a systematic review of randomized controlled trials. Heart Fail. Rev. 2020:09942. doi: 10.1007/s10741-020-09942-y
Dong, B., Qi, D., Yang, L., Huang, Y., Xiao, X., Tai, N., et al. (2012). TLR4 regulates cardiac lipid accumulation and diabetic heart disease in the nonobese diabetic mouse model of type 1 diabetes. Am. J. Physiol. Heart Circ. Physiol. 303, H732-H742. doi: 10.1152/ajpheart.00948.2011

Fadini, G. P., Menegazzo, L., Scattolini, V., Gintoli, M., Albiero, M., and Avogaro, A. (2016). A perspective on NETosis in diabetes and cardiometabolic disorders. Nutr. Metab. Cardiovasc. Dis. 26, 1-8. doi: 10.1016/j.numecd.2015.11.008

Fairweather, D. (2007). Regulating inflammation in the heart. Int. J. Biomed. Sci. 3, 9-13.

Filardi, T., Ghinassi, B., Di Baldassarre, A., Tanzilli, G., Morano, S., Lenzi, A., et al. (2019). Cardiomyopathy associated with diabetes: the central role of the cardiomyocyte. Int. J. Mol. Sci. 20:3299. doi: 10.3390/ijms20133299

Franssen, C., Chen, S., Unger, A., Korkmaz, H. I., De Keulenaer, G. W., Tschöpe, C., et al. (2016). Myocardial microvascular inflammatory endothelial activation in heart failure with preserved ejection fraction. JACC Heart Fail. 4, 312-324. doi: 10.1016/j.jchf.2015.10.007

Frati, G., Schirone, L., Chimenti, I., Yee, D., Biondi-Zoccai, G., Volpe, M., et al. (2017). An overview of the inflammatory signalling mechanisms in the myocardium underlying the development of diabetic cardiomyopathy. Cardiovasc. Res. 113, 378-388. doi: 10.1093/cvr/cvx011

Gao, Z. G., and Ye, J. P. (2012). Why do anti-inflammatory therapies fail to improve insulin sensitivity? Acta Pharmacol. Sin. 33, 182-188. doi: 10.1038/aps.2011.131

Gao, Z. Q., Yang, C., Wang, Y. Y., Wang, P., Chen, H. L., Zhang, X. D., et al. (2008). RAGE upregulation and nuclear factor-kappaB activation associated with ageing rat cardiomyocyte dysfunction. Gen. Physiol. Biophys. 27, 152-158.

Ge, T., Yu, Y., Cui, J., and Cai, L. (2019). The adaptive immune role of metallothioneins in the pathogenesis of diabetic cardiomyopathy: good or bad. Am. J. Physiol. Heart Circ. Physiol. 317, H264-H275. doi: 10.1152/ajpheart. 00123.2019

Gu, X., Shi, Y., Chen, X., Sun, Z., Luo, W., Hu, X., et al. (2020). Isoliquiritigenin attenuates diabetic cardiomyopathy via inhibition of hyperglycemia-induced inflammatory response and oxidative stress. Phytomedicine 78:153319. doi: 10. 1016/j.phymed.2020.153319

Gupta, S. C., Patchva, S., and Aggarwal, B. B. (2013). Therapeutic roles of curcumin: lessons learned from clinical trials. AAPS J. 15, 195-218. doi: 10.1208/s12248012-9432-8

Hattori, Y., Suzuki, K., Hattori, S., and Kasai, K. (2006). Metformin inhibits cytokine-induced nuclear factor kappaB activation via AMP-activated protein kinase activation in vascular endothelial cells. Hypertension 47, 1183-1188. doi: 10.1161/01.HYP.0000221429.94591.72

Hoffman, W. H., Passmore, G. G., Hannon, D. W., Talor, M. V., Fox, P., Brailer, C., et al. (2013). Increased systemic Th17 cytokines are associated with diastolic dysfunction in children and adolescents with diabetic ketoacidosis. PLoS One 8:e71905. doi: 10.1371/journal.pone.0071905

Huang, X., Qin, Z., Xu, M., Zhang, F., Jiang, X., Hua, F., et al. (2020). Neutrophil: lymphocyte ratio is positively associated with subclinical diabetic cardiomyopathy. BMC Endoc. Disord. 20:99. doi: 10.1186/s12902-020-00571-y

Itani, S. I., Ruderman, N. B., Schmieder, F., and Boden, G. (2002). Lipid-induced insulin resistance in human muscle is associated with changes in diacylglycerol, protein kinase C, and IkappaB-alpha. Diabetes 51, 2005-2011. doi: 10.2337/ diabetes.51.7.2005

Jadhav, A., Tiwari, S., Lee, P., and Ndisang, J. F. (2013). The heme oxygenase system selectively enhances the anti-inflammatory macrophage-M2 phenotype, reduces pericardial adiposity, and ameliorated cardiac injury in diabetic cardiomyopathy in Zucker diabetic fatty rats. J. Pharmacol. Exp. Ther. 345, 239-249. doi: 10.1124/jpet.112.200808

Kenny, H. C., and Abel, E. D. (2019). Heart failure in type 2 diabetes mellitus. Circ. Res. 124, 121-141. doi: 10.1161/CIRCRESAHA.118.311371

Kim, F., Pham, M., Luttrell, I., Bannerman, D. D., Tupper, J., Thaler, J., et al. (2007). Toll-like receptor-4 mediates vascular inflammation and insulin resistance in diet-induced obesity. Circ. Res. 100, 1589-1596. doi: 10.1161/CIRCRESAHA. 106.142851

Knapp, M., Tu, X., and Wu, R. (2019). Vascular endothelial dysfunction, a major mediator in diabetic cardiomyopathy. Acta Pharmacol. Sin. 40, 1-8. doi: 10. 1038/s41401-018-0042-6

Kobusiak-Prokopowicz, M., Krzysztofik, J., Kaaz, K., Jolda-Mydlowska, B., and Mysiak, A. (2018). MMP-2 and TIMP-2 in Patients with Heart Failure and 
Chronic Kidney Disease. Open Med. (Wars) 13, 237-246. doi: 10.1515/med2018-0037

Kolpakov, M. A., Sikder, K., Sarkar, A., Chaki, S., Shukla, S. K., Guo, X., et al. (2019). Inflammatory serine proteases play a critical role in the early pathogenesis of diabetic cardiomyopathy. Cell. Physiol. Biochem. 53, 982-998. doi: 10.33594/ 000000190

Koyama, Y., Takeishi, Y., Niizeki, T., Suzuki, S., Kitahara, T., Sasaki, T., et al. (2008). Soluble receptor for advanced glycation end products (RAGE) is a prognostic factor for heart failure. J. Cardiac. Fail. 14, 133-139. doi: 10.1016/j.cardfail. 2007.10.019

Kozlowska, A. S.-W. D. (2017). Flavonoids-food sources, health benefits, and mechanisms involved, Bioactive molecules in food. Cham: Springer, 1-27.

Kusaka, H., Koibuchi, N., Hasegawa, Y., Ogawa, H., and Kim-Mitsuyama, S. (2016). Empagliflozin lessened cardiac injury and reduced visceral adipocyte hypertrophy in prediabetic rats with metabolic syndrome. Cardiovasc. Diabetol. 15:157. doi: 10.1186/s12933-016-0473-7

Lehrke, M., Reilly, M. P., Millington, S. C., Iqbal, N., Rader, D. J., and Lazar, M. A. (2004). An inflammatory cascade leading to hyperresistinemia in humans. PLoS Med. 1:e45. doi: 10.1371/journal.pmed.0010045

Li, G., Yang, L., Feng, L., Yang, J., Li, Y., An, J., et al. (2020). Syringaresinol protects against Type 1 diabetic cardiomyopathy by alleviating inflammation responses, cardiac fibrosis, and oxidative stress. Mol. Nutr. Food. Res. 64:e2000231. doi: $10.1002 / \mathrm{mnfr} .202000231$

Li, L., Luo, W., Qian, Y., Zhu, W., Qian, J., Li, J., et al. (2019). Luteolin protects against diabetic cardiomyopathy by inhibiting NF-kappaB-mediated inflammation and activating the Nrf2-mediated antioxidant responses. Phytomedicine 59:152774. doi: 10.1016/j.phymed.2018.11.034

Li, S. N., Wang, X., Zeng, Q. T., Feng, Y. B., Cheng, X., Mao, X. B., et al. (2009). Metformin inhibits nuclear factor kappaB activation and decreases serum highsensitivity C-reactive protein level in experimental atherogenesis of rabbits. Heart Vessels 24, 446-453. doi: 10.1007/s00380-008-1137-7

Li, Y., Dong, J., Shang, Y., Zhao, Q., Li, P., and Wu, B. (2019). Anti-inflammatory effects of hederagenin on diabetic cardiomyopathy via inhibiting NF- $\mathrm{kB}$ and Smads signaling pathways in a type-2 diabetic mice model. RSC Adv. 9, 26238-26247. doi: 10.1039/c9ra02043h

Liberale, L., Carbone, F., Camici, G. G., and Montecucco, F. (2019). IL-1beta and statin treatment in patients with myocardial infarction and diabetic cardiomyopathy. J. Clin. Med. 8:1764. doi: 10.3390/jcm8111764

Liu, H. J., Liao, H. H., Yang, Z., and Tang, Q. Z. (2016). Peroxisome proliferator-activated receptor-gamma Is critical to cardiac fibrosis. PPAR Res. 2016:2198645. doi: 10.1155/2016/2198645

Liu, Z., Zhao, N., Zhu, H., Zhu, S., Pan, S., Xu, J., et al. (2015). Circulating interleukin-1beta promotes endoplasmic reticulum stress-induced myocytes apoptosis in diabetic cardiomyopathy via interleukin-1 receptor-associated kinase-2. Cardiovasc. Diabetol. 14:125. doi: 10.1186/s12933-015-0288-y

Luo, B., Huang, F., Liu, Y., Liang, Y., Wei, Z., Ke, H., et al. (2017). NLRP3 inflammasome as a molecular marker in diabetic cardiomyopathy. Front. Physiol. 8:519. doi: 10.3389/fphys.2017.00519

Luo, B., Li, B., Wang, W., Liu, X., Xia, Y., Zhang, C., et al. (2014). NLRP3 gene silencing ameliorates diabetic cardiomyopathy in a type 2 diabetes rat model. PLoS One 9:e104771. doi: 10.1371/journal.pone.0104771

Maier, H. J., Schips, T. G., Wietelmann, A., Kruger, M., Brunner, C., Sauter, M., et al. (2012). Cardiomyocyte-specific IkappaB kinase (IKK)/NF-kappaB activation induces reversible inflammatory cardiomyopathy and heart failure. Proc. Natl. Acad. Sci. U S A 109, 11794-11799. doi: 10.1073/pnas.1116584109

Mann, D. L. (2011). The emerging role of innate immunity in the heart and vascular system: for whom the cell tolls. Circ.Res. 108, 1133-1145. doi: 10.1161/ CIRCRESAHA.110.226936

Mann, D. L. (2015). Innate immunity and the failing heart: the cytokine hypothesis revisited. Circ. Res. 116, 1254-1268. doi: 10.1161/CIRCRESAHA.116.302317

Manolakis, A. C., Kapsoritakis, A. N., Tiaka, E. K., Sidiropoulos, A., Gerovassili, A., Satra, M., et al. (2011). TLR4 gene polymorphisms: evidence for protection against type 2 diabetes but not for diabetes-associated ischaemic heart disease. Eur. J. Endocrinol. 165, 261-267. doi: 10.1530/EJE-11-0280

Monnerat, G., Alarcon, M. L., Vasconcellos, L. R., Hochman-Mendez, C., Brasil, G., Bassani, R. A., et al. (2016). Macrophage-dependent IL-1beta production induces cardiac arrhythmias in diabetic mice. Nat. Commun. 7:13344. doi: $10.1038 /$ ncomms 13344
Nagareddy, P. R., Murphy, A. J., Stirzaker, R. A., Hu, Y., Yu, S., Miller, R. G., et al. (2013). Hyperglycemia promotes myelopoiesis and impairs the resolution of atherosclerosis. Cell Metabol. 17, 695-708. doi: 10.1016/j.cmet.2013.04.001

Naka, K. K., Pappas, K., Papathanassiou, K., Papamichael, N. D., Kazakos, N., Kanioglou, C., et al. (2010). Lack of effects of pioglitazone on cardiac function in patients with type 2 diabetes and evidence of left ventricular diastolic dysfunction: a tissue doppler imaging study. Cardiovasc. Diabetol. 9:57. doi: 10.1186/1475-2840-9-57

Natali, A., Nesti, L., Fabiani, I., Calogero, E., and Di Bello, V. (2017). Impact of empagliflozin on subclinical left ventricular dysfunctions and on the mechanisms involved in myocardial disease progression in type 2 diabetes: rationale and design of the EMPA-HEART trial. Cardiovasc. Diabetol. 16:130. doi: 10.1186/s12933-017-0615-6

Nevers, T., Salvador, A. M., Grodecki-Pena, A., Knapp, A., Velázquez, F., Aronovitz, M., et al. (2015). Left ventricular T-cell recruitment contributes to the pathogenesis of heart failure. Circ. Heart Fail. 8, 776-787. doi: 10.1161/ circheartfailure.115.002225

Nielsen, J. M., Kristiansen, S. B., Norregaard, R., Andersen, C. L., Denner, L., Nielsen, T. T., et al. (2009). Blockage of receptor for advanced glycation end products prevents development of cardiac dysfunction in $\mathrm{db} / \mathrm{db}$ type 2 diabetic mice. Eur. J. Heart Fail. 11, 638-647. doi: 10.1093/eurjhf/hfp070

Nunes, S., Soares, E., Pereira, F. C., and Reis, F. (2012). The role of inflammation in diabetic cardiomyopathy. Int. J. Infereron Cytokine Mediat. Res. 4, 59-73. doi: $10.2147 /$ ijicmr.s21679

Packer, M. (2018). Worsening heart failure during the use of DPP-4 inhibitors: pathophysiological mechanisms, clinical risks, and potential influence of concomitant antidiabetic medications. JACC Heart Fail. 6, 445-451. doi: 10. 1016/j.jchf.2017.12.016

Palomer, X., Salvado, L., Barroso, E., and Vazquez-Carrera, M. (2013). An overview of the crosstalk between inflammatory processes and metabolic dysregulation during diabetic cardiomyopathy. Int. J. Cardiol. 168, 3160-3172. doi: 10.1016/j. ijcard.2013.07.150

Pan, Y., Wang, Y., Zhao, Y., Peng, K., Li, W., Wang, Y., et al. (2014). Inhibition of JNK phosphorylation by a novel curcumin analog prevents high glucose-induced inflammation and apoptosis in cardiomyocytes and the development of diabetic cardiomyopathy. Diabetes 63, 3497-3511. doi: $10.2337 / \mathrm{db} 13-1577$

Peiró, C., Lorenzo, Ó, Carraro, R., and Sánchez-Ferrer, C. F. (2017). IL-1 $\beta$ inhibition in cardiovascular complications associated to diabetes mellitus. Front. Pharmacol. 8:363. doi: 10.3389/fphar.2017.00363

Piemonti, L., Calori, G., Lattuada, G., Mercalli, A., Ragogna, F., Garancini, M. P., et al. (2009). Association between plasma monocyte chemoattractant protein-1 concentration and cardiovascular disease mortality in middle-aged diabetic and nondiabetic individuals. Diabetes Care 32, 2105-2110. doi: 10.2337/dc09-0763

Pierzynová, A., Šrámek, J., Cinkajzlová, A., Kratochvílová, H., Lindner, J., Haluzík, M., et al. (2019). The number and phenotype of myocardial and adipose tissue CD68+ cells is associated with cardiovascular and metabolic disease in heart surgery patients. Nutr. Metabol. Cardiovas. Dis. 29, 946-955. doi: 10.1016/j. numecd.2019.05.063

Planavila, A., Iglesias, R., Giralt, M., and Villarroya, F. (2011). Sirtl acts in association with PPARalpha to protect the heart from hypertrophy, metabolic dysregulation, and inflammation. Cardiovasc. Res. 90, 276-284. doi: 10.1093/ $\mathrm{cvr} / \mathrm{cvq} 376$

Radlinger, B., Hornsteiner, F., Folie, S., Salvenmoser, W., Haubner, B. J., Schuetz, T., et al. (2020). Cardioprotective effects of short-term empagliflozin treatment in db/db mice. Sci. Rep. 10:19686. doi: 10.1038/s41598-020-76698-8

Ramasamy, R., Yan, S. F., and Schmidt, A. M. (2011). Receptor for AGE (RAGE): signaling mechanisms in the pathogenesis of diabetes and its complications. Ann. N Y Acad. Sci. 1243:88. doi: 10.1111/j.1749-6632.2011.06320.x

Reis, F., Nunes, S., and Pereira, F. (2012). The role of inflammation in diabetic cardiomyopathy. Int. J. Interf. Cytokine Mediat. Res. 4, 59-73. doi: 10.2147/ ijicmr.S21679

Ridker, P. M., Howard, C. P., Walter, V., Everett, B., Libby, P., Hensen, J., et al. (2012). Effects of interleukin-1beta inhibition with canakinumab on hemoglobin Alc, lipids, C-reactive protein, interleukin-6, and fibrinogen: a phase IIb randomized, placebo-controlled trial. Circulation 126, 2739-2748. doi: 10.1161/CIRCULATIONAHA.112.122556 
Rivera, L., Moron, R., Sanchez, M., Zarzuelo, A., and Galisteo, M. (2008). Quercetin ameliorates metabolic syndrome and improves the inflammatory status in obese Zucker rats. Obesity 16, 2081-2087. doi: 10.1038/oby.2008.315

Roslan, J., Giribabu, N., Karim, K., and Salleh, N. (2017). Quercetin ameliorates oxidative stress, inflammation and apoptosis in the heart of streptozotocinnicotinamide-induced adult male diabetic rats. Biomed. Pharmacother. 86, 570-582. doi: 10.1016/j.biopha.2016.12.044

Sanders-van Wijk, S., Tromp, J., Beussink-Nelson, L., Hage, C., Svedlund, S., Saraste, A., et al. (2020). Proteomic evaluation of the comorbidityinflammation paradigm in heart failure with preserved ejection fraction: results from the PROMIS-HFpEF study. Circulation 142, 2029-2044. doi: 10.1161/ CIRCULATIONAHA.120.045810

Sarkar, A., Shukla, S. K., Alqatawni, A., Kumar, A., Addya, S., Tsygankov, A. Y., et al. (2018). The role of allograft inflammatory factor-1 in the effects of experimental diabetes on B cell functions in the heart. Front. Cardiovasc. Med. 5:126. doi: $10.3389 /$ fcvm.2018.00126

Scheen, A. J. (2020). Sodium-glucose cotransporter type 2 inhibitors for the treatment of type 2 diabetes mellitus. Nat. Rev. Endocrinol. 16, 556-577. doi: 10.1038/s41574-020-0392-2

Schilling, J. D. (2015). The mitochondria in diabetic heart failure: from pathogenesis to therapeutic promise. Antioxid Redox Signal 22, 1515-1526. doi: 10.1089/ars.2015.6294

Sciarretta, S., Ferrucci, A., Ciavarella, G. M., De Paolis, P., Venturelli, V., Tocci, G., et al. (2007). Markers of inflammation and fibrosis are related to cardiovascular damage in hypertensive patients with metabolic syndrome. Am. J. Hyperten. 20, 784-791. doi: 10.1016/j.amjhyper.2007.01.023

Shah, Z., Kampfrath, T., Deiuliis, J. A., Zhong, J., Pineda, C., Ying, Z., et al. (2011). Long-term dipeptidyl-peptidase 4 inhibition reduces atherosclerosis and inflammation via effects on monocyte recruitment and chemotaxis. Circulation 124, 2338-2349. doi: 10.1161/CIRCULATIONAHA.111.041418

Shaher, F., Wang, S., Qiu, H., Hu, Y., Zhang, Y., Wang, W., et al. (2020). Effect and mechanism of Ganoderma lucidum spores on alleviation of diabetic cardiomyopathy in a pilot in vivo study. Diabetes Metab. Syndr. Obes. 13, 4809-4822. doi: 10.2147/DMSO.S281527

Singla, D. K., Singla, R. D., Abdelli, L. S., and Glass, C. (2015). Fibroblast growth factor-9 enhances M2 macrophage differentiation and attenuates adverse cardiac remodeling in the infarcted diabetic heart. PLoS One 10:e0120739. doi: 10.1371/journal.pone.0120739

Stienstra, R., van Diepen, J. A., Tack, C. J., Zaki, M. H., van de Veerdonk, F. L., Perera, D., et al. (2011). Inflammasome is a central player in the induction of obesity and insulin resistance. Proc. Natl. Acad. Sci. U S A. 108, 15324-15329. doi: 10.1073/pnas.1100255108

Suresh Babu, S., Thandavarayan, R. A., Joladarashi, D., Jeyabal, P., Krishnamurthy, S., Bhimaraj, A., et al. (2016). MicroRNA-126 overexpression rescues diabetesinduced impairment in efferocytosis of apoptotic cardiomyocytes. Sci. Rep. 6:36207. doi: 10.1038/srep36207

Suzuki, T., Katz, R., Jenny, N. S., Zakai, N. A., LeWinter, M. M., Barzilay, J. I., et al. (2008). Metabolic syndrome, inflammation, and incident heart failure in the elderly: the cardiovascular health study. Circ. Heart Fail. 1, 242-248. doi: 10.1161/CIRCHEARTFAILURE.108.785485

Tan, X., Hu, L., Shu, Z., Chen, L., Li, X., Du, M., et al. (2019). Role of CCR2 in the development of streptozotocin-treated diabetic cardiomyopathy. Diabetes 68, 2063-2073. doi: 10.2337/db18-1231

Tan, Y., Ichikawa, T., Li, J., Si, Q., Yang, H., Chen, X., et al. (2011). Diabetic downregulation of $\mathrm{Nrf} 2$ activity via ERK contributes to oxidative stress-induced insulin resistance in cardiac cells in vitro and in vivo. Diabetes 60, 625-633. doi: $10.2337 / \mathrm{db} 10-1164$

Tan, Y., Zhang, Z., Zheng, C., Wintergerst, K. A., Keller, B. B., and Cai, L. (2020). Mechanisms of diabetic cardiomyopathy and potential therapeutic strategies: preclinical and clinical evidence. Nat. Rev. Cardiol. 17, 585-607. doi: 10.1038/ s41569-020-0339-2

Thomas, C. M., Yong, Q. C., Rosa, R. M., Seqqat, R., Gopal, S., Casarini, D. E., et al. (2014). Cardiac-specific suppression of NF-kappaB signaling prevents diabetic cardiomyopathy via inhibition of the renin-angiotensin system. Am. J. Physiol. Heart Circ. Physiol. 307, H1036-H1045. doi: 10.1152/ajpheart.00340.2014

Tikellis, C., Thomas, M. C., Harcourt, B. E., Coughlan, M. T., Pete, J., Bialkowski, K., et al. (2008). Cardiac inflammation associated with a Western diet is mediated via activation of RAGE by AGEs. Am. J. Physiol. Endocrinol. Metab. 295, E323-E330. doi: 10.1152/ajpendo.00024.2008

Torre-Amione, G., Anker, S. D., Bourge, R. C., Colucci, W. S., Greenberg, B. H., Hildebrandt, P., et al. (2008). Results of a non-specific immunomodulation therapy in chronic heart failure (ACCLAIM trial): a placebo-controlled randomised trial. Lancet 371, 228-236. doi: 10.1016/S0140-6736(08)60134-8

Trang, N. N., Chung, C. C., Lee, T. W., Cheng, W. L., Kao, Y. H., Huang, S. Y., et al. (2021). Empagliflozin and liraglutide differentially modulate cardiac metabolism in diabetic cardiomyopathy in rats. Int. J. Mol. Sci. 22:1177. doi: 10.3390/ijms 22031177

Tromp, J., Voors, A. A., Sharma, A., Ferreira, J. P., Ouwerkerk, W., Hillege, H. L., et al. (2020). Distinct pathological pathways in patients with heart failure and diabetes. JACC Heart Fail. 8, 234-242. doi: 10.1016/j.jchf.2019.11.005

Troseid, M., Seljeflot, I., Hjerkinn, E. M., and Arnesen, H. (2009). Interleukin-18 is a strong predictor of cardiovascular events in elderly men with the metabolic syndrome: synergistic effect of inflammation and hyperglycemia. Diabetes Care 32, 486-492. doi: $10.2337 / \mathrm{dc} 08-1710$

Urbina, P., and Singla, D. K. (2014). BMP-7 attenuates adverse cardiac remodeling mediated through M2 macrophages in prediabetic cardiomyopathy. Am. J. Physiol. Heart Circ. Physiol. 307, H762-H772. doi: 10.1152/ajpheart.00367.2014

Van Linthout, S., Seeland, U., Riad, A., Eckhardt, O., Hohl, M., Dhayat, N., et al. (2008). Reduced MMP-2 activity contributes to cardiac fibrosis in experimental diabetic cardiomyopathy. Basic Res. Cardiol. 103, 319-327. doi: 10.1007/ s00395-008-0715-2

Van Linthout, S., and Tschope, C. (2017). Inflammation - cause or consequence of heart failure or both? Curr. Heart Fail. Rep. 14, 251-265. doi: 10.1007/s11897017-0337-9

Vasamsetti, S. B., Karnewar, S., Kanugula, A. K., Thatipalli, A. R., Kumar, J. M., and Kotamraju, S. (2015). Metformin inhibits monocyte-to-macrophage differentiation via AMPK-mediated inhibition of STAT3 activation: potential role in atherosclerosis. Diabetes 64, 2028-2041. doi: 10.2337/db14- 1225

Verweij, S. L., Duivenvoorden, R., Stiekema, L. C. A., Nurmohamed, N. S., van der Valk, F. M., Versloot, M., et al. (2018). CCR2 expression on circulating monocytes is associated with arterial wall inflammation assessed by $18 \mathrm{~F}-\mathrm{FDG}$ PET/CT in patients at risk for cardiovascular disease. Cardiovasc. Res. 114, 468-475. doi: 10.1093/cvr/cvx224

Volz, H. C., Seidel, C., Laohachewin, D., Kaya, Z., Müller, O. J., Pleger, S. T., et al. (2010). HMGB1: the missing link between diabetes mellitus and heart failure. Basic Res. Cardiol. 105, 805-820. doi: 10.1007/s00395-010-0114-3

von Bibra, H., Diamant, M., Scheffer, P. G., Siegmund, T., and Schumm-Draeger, P. M. (2008). Rosiglitazone, but not glimepiride, improves myocardial diastolic function in association with reduction in oxidative stress in type 2 diabetic patients without overt heart disease. Diab. Vasc. Dis. Res. 5, 310-318. doi: 10.3132/dvdr.2008.045

Wang, L. J., Lu, L., Zhang, F. R., Chen, Q. J., De Caterina, R., and Shen, W. F. (2011). Increased serum high-mobility group box-1 and cleaved receptor for advanced glycation endproducts levels and decreased endogenous secretory receptor for advanced glycation endproducts levels in diabetic and non-diabetic patients with heart failure. Eur. J. Heart Fail. 13, 440-449. doi: 10.1093/eurjhf/hfq231

Wang, W., Wang, B., Lu, Q., Zhang, W., Qin, W., Liu, X., et al. (2014). Inhibition of high-mobility group box 1 improves myocardial fibrosis and dysfunction in diabetic cardiomyopathy. Int. J. Cardiol. 172, 202-212. doi: 10.1016/j.ijcard. 2014.01.011

Wang, X. T., Gong, Y., Zhou, B., Yang, J. J., Cheng, Y., Zhao, J. G., et al. (2018). Ursolic acid ameliorates oxidative stress, inflammation and fibrosis in diabetic cardiomyopathy rats. Biomed. Pharmacother. 97, 1461-1467. doi: 10.1016/j. biopha.2017.11.032

Wang, Y., Feng, W., Xue, W., Tan, Y., Hein, D. W., Li, X. K., et al. (2009). Inactivation of GSK-3beta by metallothionein prevents diabetes-related changes in cardiac energy metabolism, inflammation, nitrosative damage, and remodeling. Diabetes 58, 1391-1402. doi: 10.2337/db08-1697

Wang, Y., Luo, W., Han, J., Khan, Z. A., Fang, Q., Jin, Y., et al. (2020). MD2 activation by direct AGE interaction drives inflammatory diabetic cardiomyopathy. Nat. Commun. 11:2148. doi: 10.1038/s41467-020-15978-3

Wang, Y., Zhou, S., Sun, W., McClung, K., Pan, Y., Liang, G., et al. (2014). Inhibition of JNK by novel curcumin analog C66 prevents diabetic cardiomyopathy with a preservation of cardiac metallothionein expression. Am. 
J. Physiol. Endocrinol. Metab. 306, E1239-E1247. doi: 10.1152/ajpendo.00629. 2013

Wei, H., Bu, R., Yang, Q., Jia, J., Li, T., Wang, Q., et al. (2019). Exendin4 protects against hyperglycemia-induced cardiomyocyte pyroptosis via the AMPK-TXNIP pathway. J. Diabetes Res. 2019:8905917. doi: 10.1155/2019/ 8905917

Westermann, D., Van Linthout, S., Dhayat, S., Dhayat, N., Escher, F., Bucker-Gartner, C., et al. (2007a). Cardioprotective and anti-inflammatory effects of interleukin converting enzyme inhibition in experimental diabetic cardiomyopathy. Diabetes 56, 1834-1841. doi: 10.2337/db06-1662

Westermann, D., Van Linthout, S., Dhayat, S., Dhayat, N., Schmidt, A., Noutsias, M., et al. (2007b). Tumor necrosis factor-alpha antagonism protects from myocardial inflammation and fibrosis in experimental diabetic cardiomyopathy. Basic Res. Cardiol. 102, 500-507. doi: 10.1007/s00395-0070673-0

Wong, S. L., Demers, M., Martinod, K., Gallant, M., Wang, Y., Goldfine, A. B., et al. (2015). Diabetes primes neutrophils to undergo NETosis, which impairs wound healing. Nat. Med. 21, 815-819. doi: 10.1038/nm.3887

Yang, W. H., Park, S. Y., Nam, H. W., Kim, D. H., Kang, J. G., Kang, E. S., et al. (2008). NFkappaB activation is associated with its O-GlcNAcylation state under hyperglycemic conditions. Proc. Natl. Acad. Sci. U S A 105, 17345-17350. doi: 10.1073/pnas.0806198105

Ye, Y., Bajaj, M., Yang, H. C., Perez-Polo, J. R., and Birnbaum, Y. (2017). SGLT-2 inhibition with Dapagliflozin reduces the activation of the Nlrp3/ASC inflammasome and attenuates the development of diabetic cardiomyopathy in mice with type 2 diabetes. Further augmentation of the effects with saxagliptin, a DPP4 inhibitor. Cardiovasc. Drugs Ther. 31, 119-132. doi: 10.1007/s10557017-6725-2

Younce, C. W., Wang, K., and Kolattukudy, P. E. (2010). Hyperglycaemia-induced cardiomyocyte death is mediated via MCP-1 production and induction of a novel zinc-finger protein MCPIP. Cardiovasc. Res. 87, 665-674. doi: 10.1093/ cvr/cvq102

Zahedi, M., Ghiasvand, R., Feizi, A., Asgari, G., and Darvish, L. (2013). Does quercetin improve cardiovascular risk factors and inflammatory biomarkers in women with type 2 diabetes: a double-blind randomized controlled clinical trial. Int. J. Prev. Med. 4, 777-785.

Zannad, F., Ferreira, J. P., Pocock, S. J., Anker, S. D., Butler, J., Filippatos, G., et al. (2020). SGLT2 inhibitors in patients with heart failure with reduced ejection fraction: a meta-analysis of the EMPEROR-Reduced and DAPA-HF trials. Lancet 396, 819-829. doi: 10.1016/S0140-6736(20)31824-9
Zeng, C., Shi, X., Zhang, B., Liu, H., Zhang, L., Ding, W., et al. (2012). The imbalance of Th17/Th1/Tregs in patients with type 2 diabetes: relationship with metabolic factors and complications. J. Mol. Med. 90, 175-186. doi: 10.1007/ s00109-011-0816-5

Zhang, Y., Li, Y., Huang, X., Zhang, F., Tang, L., Xu, S., et al. (2020). Systemic delivery of siRNA specific for silencing TLR4 gene expression reduces diabetic cardiomyopathy in a mouse model of streptozotocin-induced type 1 diabetes. Diabetes Ther. 11, 1161-1173. doi: 10.1007/s13300-020-00802-4

Zhang, Y., Wang, J.-H., Zhang, Y.-Y., Wang, Y.-Z., Wang, J., Zhao, Y., et al. (2016). Deletion of interleukin-6 alleviated interstitial fibrosis in streptozotocininduced diabetic cardiomyopathy of mice through affecting TGF $\beta 1$ and miR-29 pathways. Sci. Rep. 6, 1-11. doi: 10.1155/2020/9481720

Zheng, J., Cheng, J., Zheng, S., Feng, Q., and Xiao, X. (2018). Curcumin, a polyphenolic curcuminoid with its protective effects and molecular mechanisms in diabetes and diabetic cardiomyopathy. Front. Pharmacol. 9:472. doi: 10.3389/fphar.2018.00472

Zhong, J., Maiseyeu, A., Davis, S. N., and Rajagopalan, S. (2015). DPP4 in cardiometabolic disease: recent insights from the laboratory and clinical trials of DPP4 inhibition. Circ. Res. 116, 1491-1504. doi: 10.1161/CIRCRESAHA.116. 305665

Zhou, H., Wang, S., Zhu, P., Hu, S., Chen, Y., and Ren, J. (2018). Empagliflozin rescues diabetic myocardial microvascular injury via AMPKmediated inhibition of mitochondrial fission. Redox Biol. 15, 335-346. doi: 10.1016/j.redox.2017.12.019

Zou, F., Wang, L., Liu, H., Wang, W., Hu, L., Xiong, X., et al. (2019). Sophocarpine suppresses NF-kappaB-mediated inflammation both in vitro and in vivo and inhibits diabetic cardiomyopathy. Front. Pharmacol. 10:1219. doi: 10.3389/ fphar.2019.01219

Conflict of Interest: The authors declare that the research was conducted in the absence of any commercial or financial relationships that could be construed as a potential conflict of interest.

Copyright (c) 2021 Kaur, Guan, Raja, Ruiz-Velasco and Liu. This is an open-access article distributed under the terms of the Creative Commons Attribution License (CC BY). The use, distribution or reproduction in other forums is permitted, provided the original author(s) and the copyright owner(s) are credited and that the original publication in this journal is cited, in accordance with accepted academic practice. No use, distribution or reproduction is permitted which does not comply with these terms. 